\title{
The effectiveness of Schroth exercises in adolescents with idiopathic scoliosis: A systematic review and meta-analysis
}

\begin{tabular}{|c|c|}
\hline \multicolumn{2}{|c|}{$\begin{array}{l}\text { Authors: } \\
\text { Marlette Burger }{ }^{1} \\
\text { Wilna Coetzee }^{1} \\
\text { Lenka Z. du Plessis }^{1} \\
\text { Larissa Geldenhuys }^{1} \\
\text { Francois Joubert }^{1} \\
\text { Elzanne Myburgh }^{1} \\
\text { Chante van Rooyen }^{1} \\
\text { Nicol Vermeulen }\end{array}$} \\
\hline \multicolumn{2}{|c|}{$\begin{array}{l}\text { Affiliations: } \\
{ }^{1} \text { Department of Health and } \\
\text { Rehabilitation Sciences, } \\
\text { Stellenbosch University, } \\
\text { Cape Town, South Africa }\end{array}$} \\
\hline \multicolumn{2}{|c|}{$\begin{array}{l}\text { Corresponding author: } \\
\text { Marlette Burger, } \\
\text { mbu@sun.ac.za }\end{array}$} \\
\hline \multicolumn{2}{|c|}{$\begin{array}{l}\text { Dates: } \\
\text { Received: } 10 \text { Oct. } 2018 \\
\text { Accepted: } 05 \text { Feb. } 2019 \\
\text { Published: } 03 \text { June } 2019\end{array}$} \\
\hline \multicolumn{2}{|c|}{$\begin{array}{l}\text { How to cite this article: } \\
\text { Burger, M., Coetzee, W., } \\
\text { Du Plessis, L.Z., Geldenhuys, L., } \\
\text { Joubert, F., Myburgh, E., } \\
\text { et al., 2019, 'The effectiveness } \\
\text { of Schroth exercises in } \\
\text { adolescents with idiopathic } \\
\text { scoliosis: A systematic } \\
\text { review and meta-analysis', } \\
\text { South African Journal of } \\
\text { Physiotherapy 75(1), } \\
\text { a904. https://doi.org/ } \\
\text { 10.4102/sajp.v75i1.904 }\end{array}$} \\
\hline \multicolumn{2}{|c|}{$\begin{array}{l}\text { Copyright: } \\
\text { (c) 2019. The Authors. } \\
\text { Licensee: AOSIS. This wo } \\
\text { is licensed under the } \\
\text { Creative Commons } \\
\text { Attribution License. }\end{array}$} \\
\hline \multicolumn{2}{|l|}{ Read online: } \\
\hline 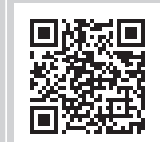 & $\begin{array}{l}\text { Scan this QR } \\
\text { code with your } \\
\text { smart phone or } \\
\text { mobile device } \\
\text { to read online. }\end{array}$ \\
\hline
\end{tabular}

Background: Adolescent idiopathic scoliosis (AIS) is one of the most common structural spinal deformities in adolescents, becoming apparent around the time of puberty. Schroth scoliosis-specific exercises have demonstrated promising results in reducing the progression of AIS.

Objectives: The aim of this study was to identify, critically appraise and establish the best available evidence for the effectiveness of Schroth exercises in comparison to non-surgical management to reduce the progression of AIS.

Methodology: Seven databases were searched in April 2018. Main key search terms included AIS, Schroth exercises, physiotherapy, exercise, electrical stimulation, yoga, Pilates, tai chi and bracing. The quality of the trials was critically appraised according to the PEDro scale. Revman(C) Review Manager Software was used to pool the quality of life (QOL) results.

Results: Four randomised control trials with an average PEDro score of 6.75/10 were included in this study. Results indicated that Schroth exercises had a significant effect in decreasing the Cobb angle $(p<0.05)$ in comparison to non-surgical management. The pooled effect on QOL showed a significant result in favour of Schroth exercises at 12 weeks $(p<0.002)$ and at 24 weeks $(p<0.0004)$.

Conclusion: Level II evidence suggests that Schroth exercises have a significant effect on reducing the Cobb angle and improving QOL in adolescents with idiopathic scoliosis.

Clinical implications: This review's findings should be considered with caution for physiotherapy practice because of the limited number of identified articles and their methodologic limitations. Based on the current available and limited evidence, clinicians could combine supervised Schroth exercises with conventional physiotherapy care (observation, exercise, bracing and manual therapy) when treating adolescents with idiopathic scoliosis.

Keywords: adolescent idiopathic scoliosis; Schroth exercises; physiotherapy; Cobb angle; quality of life; systematic review; meta-analysis.

\section{Introduction}

Adolescent idiopathic scoliosis (AIS) is the most common structural spinal deformity occurring in adolescents (Cheng et al. 2017). Adolescent idiopathic scoliosis presents as a laterally rotated curvature of the spine and becomes apparent in generally healthy children around the time of puberty (Weinstein et al. 2008). Adolescent idiopathic scoliosis is diagnosed when the spinal curvature in the coronal plane is equal to or greater than 10 degrees. This spinal curvature is known as the Cobb angle (Cheng et al. 2017), and it is determined by measuring the angle between the upper and lower limits of the deformity in the coronal plane (Morrissy et al. 1990). The magnitude of the Cobb angle is used for classification or to categorise the severity of the scoliosis (Romano et al. 2012). A curve of up to $25^{\circ}$ is considered a mild form of scoliosis. Values between $25^{\circ}$ and $45^{\circ}$ are classified as being a moderate form of this condition and a curve above $45^{\circ}$ as severe scoliosis (Romano et al. 2012). If the spinal curve is more than $30^{\circ}$ at the end of growth, the potential risks in adulthood increase significantly. These potential risks include pain, deformity of the thorax and shoulder girdle, decreased quality of life (QOL), disability and possible respiratory problems that can progress during adulthood (Altaf et al. 2013; Romano et al. 2012).

Idiopathic scoliosis has traditionally been described as a pain-free condition (Choudhry, Ahmad \& Verma 2016). However, a study conducted by Ramirez, Johnston and Brown (1997) found that 
$31.5 \%$ of patients with scoliosis presented with back pain. Patients with idiopathic scoliosis usually only complain of back pain and/or radicular symptoms when they have reached adulthood. Back pain may be the result of spinal imbalance, facet arthropathy, muscle imbalance and fatigue, or foraminal stenosis (Agabegi et al. 2015).

Scoliosis can lead to prolonged incorrect postures and can influence self-image tremendously, especially in the younger female population (Asher \& Burton 2006). This in itself can lead to psychological disturbances such as depression (Asher \& Burton 2006). Pulmonary impairment manifesting as shortness of breath can be significant in Cobb angles bigger than $80^{\circ}$ and in cases where thoracic rotation is present (Asher \& Burton 2006). Reduced exercise tolerance, reduced diffusion capacity and a lower maximum oxygen consumption $\left(\mathrm{VO}_{2}\right.$ max) can also be evident in patients with moderate to severe curves (Agabegi et al. 2015). Patients with scoliosis can easily maintain a normal level of functional activity with regard to occupation and family; however, some physical activities, such as lifting, prolonged sitting and standing, and walking long distances can be demanding (Agabegi et al. 2015; Asher \& Burton 2006). Therefore, once the diagnosis has been made, effective management should be instituted immediately to address the deformity and to prevent its long-term sequelae.

The non-surgical management of AIS includes observation and conservative treatment. Observation is the first approach to idiopathic scoliosis, and it is performed by regular clinical assessment with a specific follow-up period. When the curvature is less than $25^{\circ}$, the patient is normally observed every 6 to 12 months (Weiss, Weiss \& Petermann 2003). The main goals of conservative treatment of AIS are the prevention of curve progression and the cosmetic improvement of the trunk (Vasiliadis \& Grivas 2008). The most common interventions used in conservative treatment of AIS are bracing, exercise therapy and manual therapy (Lewis 2012). Bracing is the application of external support to the trunk, and it is used to straighten the spine and de-rotate the pelvis and shoulders to try to achieve normal alignment of the entire body (Rigo et al. 2006). This method of treatment is indicated if the Cobb angle is larger than $25^{\circ}$ (Richards et al. 2005). The external and proprioceptive effects resulting from bracing lead to changes in the abnormal loading on the spine and rib cage, reducing asymmetrical movements and increasing neuromuscular control. This facilitates correct spinal growth and neuromotor reorganisation, as well as changes in motor behaviours (Negrini et al. 2010). The outcome of bracing, however, is directly related to compliance, as it should be worn for a prolonged time (minimum of $23 \mathrm{~h}$ /day) over several years until skeletal maturity is reached, which generally occurs at 16 years of age for females and 18 years of age for males (Katz \& Durrani 2001). Bracing can also be a stressful experience for patients and can worsen self-image and body image, interactions with others and total QOL, which is already impacted by the condition of AIS (Reichel \& Schanz 2003). Most braces have the disadvantage of being very bulky and uncomfortable to wear, especially for long periods, and this leads to non-compliance of brace-wear (Canavese \& Kaelin 2011).

The overall aim of exercise therapy and specific exercises is to reduce the progression of the scoliotic deformity and to delay or avoid the need of wearing a brace (Romano et al. 2013). Adolescent patients with idiopathic scoliosis with thoracic Cobb angles up to $25^{\circ}$ and lumbar or thoraco-lumbar curves up to $20^{\circ}$ receive exercises alone, while patients with thoracic main curves between $25^{\circ}$ and $50^{\circ}$ and lumbar or thoracolumbar curves between $20^{\circ}$ and $40^{\circ}$ receive bracing combined with an exercise regime (Monticone et al. 2014). Exercises to address scoliosis include physical exercises such as strengthening, mobilising, machine-assisted exercises, electrical stimulation, breathing and postural correction exercises (Monticone et al. 2014), as well as low-impact exercises like Pilates, yoga or tai chi to improve trunk flexibility and strength (Blum 2002; Romano et al. 2012).

The Schroth method of exercise is a scoliosis-specific modality used to treat idiopathic scoliosis in young adolescents (Schreiber et al. 2016). In an updated systematic review, Fusco et al. (2011) showed a marked improvement in back strength and breathing function, as well as slowing the rate of curve progression and decreasing the Cobb angle in AIS, when using Schroth exercises. Schroth exercises are described as a 'method that consists of sensorimotor, postural and breathing exercises aimed at recalibration of normal postural alignment, static/dynamic postural control, and spinal stability' (Schreiber et al. 2016). In addition to improving various measures of scoliosis, functionality and QOL, Schreiber et al. (2015) reported that adolescents with curves between $10^{\circ}$ and $45^{\circ}$ responded well to Schroth exercises, resulting in an increase in self-esteem and improved psychological outcomes.

To date, no systematic review comparing the effectiveness of Schroth exercises versus non-surgical management (including observation or conservative management such as the wear of a brace and/or exercise therapy) has been conducted. Several systematic reviews have been published on the effect of exercise in the management of idiopathic scoliosis (Berdishevsky et al. 2016; Romano et al. 2012), but none of them focused on Schroth exercises. Park, Jeon and Park (2017) published a meta-analysis focusing on the effects of Schroth exercise on idiopathic scoliosis; however, they mainly focused on the overall effect size of pre- and postSchroth exercise subgroup analyses and did not report between-group analyses. The different subgroups were Cobb's angle ranges, treatment durations and specific Schroth exercises. They found that Schroth exercises practised for at least 1 month were more beneficial for scoliosis patients who had a $10^{\circ}$ to $30^{\circ} \mathrm{Cobb}$ 's angle compared to those with a Cobb's angle greater than $30^{\circ}$.

The aim of this systematic review was to identify, critically appraise, evaluate and establish best current available evidence on the effectiveness of Schroth exercises to reduce 
the Cobb angle and improve QOL compared to non-surgical management (including observation or conservative management) in patients with AIS. This will ensure that clinicians have access to the best current available evidence to assist them in the management of adolescents with idiopathic scoliosis.

\section{Methodology}

The Preferred Reporting Items for Systematic Reviews and Meta-Analyses (PRISMA) guidelines were strictly adhered to during the conduct of this systematic review and metaanalysis (Liberati et al. 2009).

\section{Search strategy}

The following seven computerised bibliographic databases, accessed through the Stellenbosch Library services, were searched: PubMed; Science Direct; EBSCOhost: CINAHL and MEDLINE; Cochrane Library; PEDro; Scopus and ProQuest Medical Library. Stepwise documentation of the entire search process was implemented. Key search terms included AIS, juvenile idiopathic scoliosis, Schroth exercises, physiotherapy, physical therapy, exercise, electrical stimulation, yoga, Pilates, tai chi and bracing. Each database received an individual search strategy according to its function. The databases were divided among the group members, with two authors assigned to each database. The two authors independently searched their allocated database by using the same strategy to ensure proper cross-checking of the results obtained within the different databases. Every database was submitted to the same process and each part of the search process was recorded, documented and cross-checked. Based on the inclusion and exclusion criteria that follow, the authors independently reviewed the titles, abstracts and full-text articles retrieved in the initial search. The authors compared the eligible articles selected for inclusion, and disagreements regarding accepting full-text articles were discussed until consensus was achieved.

\section{Study inclusion and exclusion criteria}

The following inclusion and exclusion criteria were applied.

\section{Type of studies}

Only randomised controlled trials (RCTs) published in English from inception of the databases until April 2018, scoring at least $4 / 10$ on the PEDro scale (Verhagen et al. 1998), were eligible for inclusion in this review.

\section{Type of participants}

Study participants could include males and females between the ages of 10 and 19 , with a scoliotic curvature of $10^{\circ}$ or more (measured by using the Cobb angle). Randomised controlled trials were excluded if they included participants with a scoliotic curvature of less than $10^{\circ}$ or if they included participants with scoliosis caused by other pathologies not defined as idiopathic scoliosis.

\section{Types of interventions}

Studies in which participants received only Schroth exercises as the intervention were included.

\section{Types of comparisons}

The comparison group had to include participants who received non-surgical management (including observation or conservative management). Conservative management could include the following: wear of brace and/or an exercise regime (including but not confined to stretches, strengthening, mobilising exercises, exercises involving electrical stimulation of specific muscle groups, yoga, Pilates or tai chi).

\section{Type of outcomes}

Studies that used the Cobb angle as the outcome measure and/or studies that used a QOL questionnaire as the outcome measure were included.

\section{Evidence hierarchy and methodological appraisal}

The relevant articles that met the inclusion criteria for this systematic review were appraised using the National Health and Medical Research Council (NHMRC) hierarchy of evidence (Coleman et al. 2009).

The use of Level II evidence is considered the best for answering intervention questions in a systematic review, whereas Level III and IV evidence becomes progressively less valid and reliable (Coleman et al. 2009). Methodological quality of each included article was appraised using the PEDro scale. The scale appraises internal validity and statistical reporting according to 10 criteria; it is a valid and reliable assessment of the methodological quality of clinical trials (de Morton 2009). Each included article was assigned to two reviewers, who scored the article independently using the PEDro scale. Following this, the two reviewers then compared their scores and, if there were any discrepancies, a third reviewer was consulted. If consensus was still not reached, a group discussion between all eight authors was held to resolve the matter.

\section{Data extraction and analysis method}

The data were extracted and captured on a Microsoft Excel spreadsheet by one author to ensure continuity. Data extracted from the articles included the following categories: citation, study type, participants, interventions, comparisons, outcome measures, results, post-intervention clinical status and implications. The rest of the seven research team members cross-checked the information independently.

Mutual consensus among the group was ensured after a discussion of the complete data extraction. Data pertaining to QOL were synthesised in the form of meta-analyses using the RevMan@ Review Manager Software (RevMan@ Information Management System 2008), utilising a fixed-effects approach to illustrate combined effects in the form of forest plots. Because the included articles used different versions of 
the Scoliosis Research Society's (SRS) health-related QOL questionnaire (https://www.srs.org/professionals/onlineeducation-and-resources/patient-outcome-questionnaires), we used the standardised mean difference in RevMan to convert and standardise the QOL outcomes to a uniform scale. We pooled the means and standard deviations from individual studies to obtain overall estimates and 95\% confidence intervals (CIs).

Statistical pooling for the Cobb angle to measure the spinal curvature was considered inappropriate owing to heterogeneity among reporting of results, which were subsequently summarised in a narrative form and illustrated in a table.

\section{Ethical considerations}

This study consists of secondary research, thus ethical approval was not required for this systematic review and meta-analysis.

\section{Results}

\section{Search results}

A total number of 288 initial hits were found in the seven databases; of these, 244 irrelevant articles were removed. There were 44 remaining potential titles and abstracts reviewed. Out of these 44 titles and abstracts, 11 were excluded because they were duplicates. After removing the 11 duplicate articles, 33 full-text articles remained. These fulltext articles were assessed according to the inclusion and exclusion criteria as set out for this study. Twenty-nine fulltext articles did not meet the requirements of the inclusion criteria, leaving only four full-text articles suitable to analyse in this systematic review. The search strategy and results are illustrated in Figure 1.

\section{Evidence hierarchy and methodological appraisal}

According to the hierarchy of evidence set forth by the NHMRC (2009), the four included articles (Kim \& HwangBo 2016; Kuru et al. 2016; Schreiber et al. 2015, 2016) were classified as Level II. The methodological quality of the four included articles, according to the PEDro scale, ranged between $5 / 10$ to $8 / 10$, with an average score of $6.75 / 10$ (see Table 1). Because of the nature of the included articles, Criteria 4 and 5 (blinding of subjects and therapists) were not met in any of the studies. Kim and HwangBo (2016) and Kuru et al. (2016) also did not blind the assessors in their respective studies.

\section{Description of study sample}

Table 1 summarises the sample descriptions and interventions of the four included RCTs. All articles had small sample sizes, contributing to a total sample size of 119 participants, consisting of 67 in the intervention groups and 52 in the control groups. Schreiber et al. (2015) and Schreiber et al.

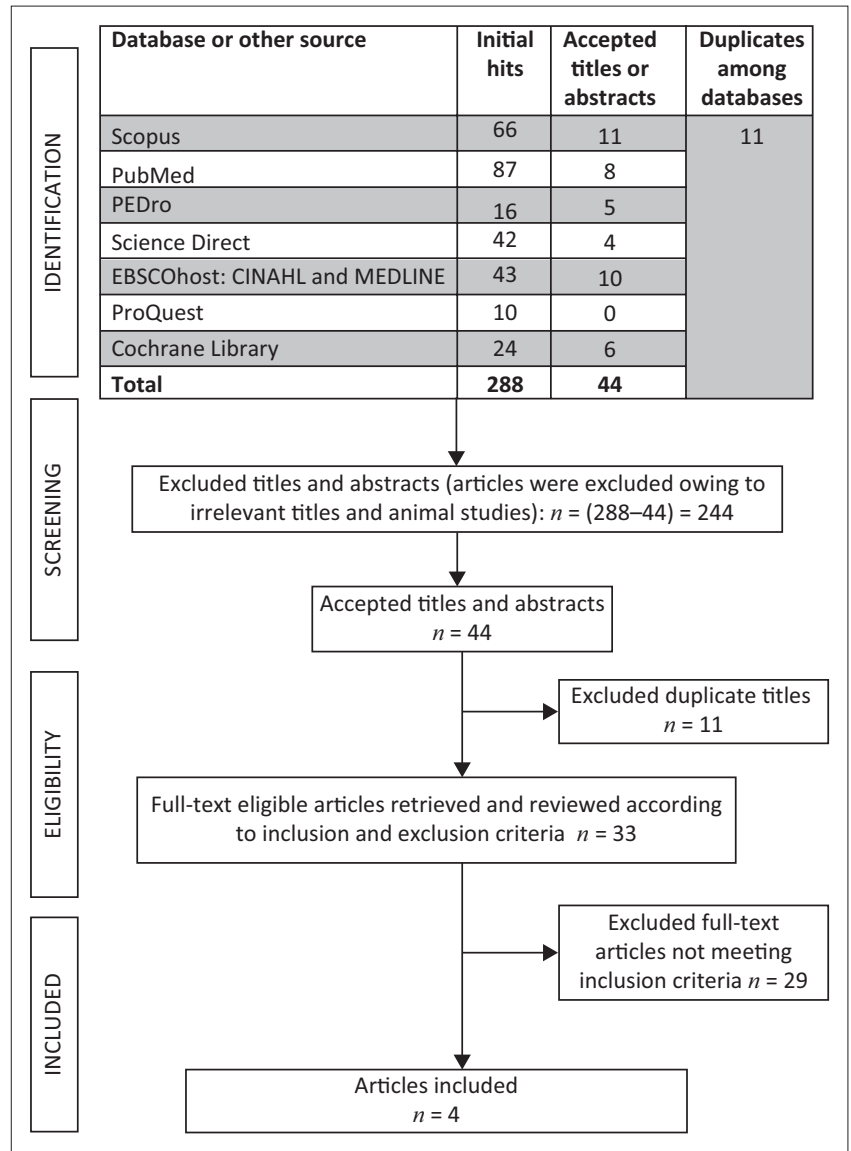

FIGURE 1: Search results.

TABLE 1: Study sample description.

\begin{tabular}{|c|c|c|c|c|}
\hline Criteria & Variables & $\begin{array}{l}\text { Schreiber et al. (2015) } \\
\text { and Schreiber et al. } \\
(2016)\end{array}$ & $\begin{array}{c}\text { Kim and } \\
\text { HwangBo } \\
\text { (2016) }\end{array}$ & $\begin{array}{l}\text { Kuru et al. } \\
\text { (2016) }\end{array}$ \\
\hline \multirow{3}{*}{$\begin{array}{l}\text { Sample size } \\
(n)\end{array}$} & Schroth exercises & 25 & 12 & 15 \\
\hline & Home exercises & - & - & 15 \\
\hline & $\begin{array}{l}\text { Non-surgical } \\
\text { management }\end{array}$ & 25 & 12 & 15 \\
\hline \multirow[t]{3}{*}{$\begin{array}{l}\text { Gender } \\
(n)\end{array}$} & Schroth exercises & $\begin{array}{c}\text { Female }=23 \\
\text { Male }=2\end{array}$ & $\begin{array}{c}\text { Female }=12 \\
\text { Male }=0\end{array}$ & $\begin{array}{c}\text { Female }=14 \\
\text { Male }=1\end{array}$ \\
\hline & Home exercises & - & - & $\begin{array}{c}\text { Female }=12 \\
\text { Male }=3\end{array}$ \\
\hline & $\begin{array}{l}\text { Non-surgical } \\
\text { management }\end{array}$ & $\begin{array}{c}\text { Female }=24 \\
\text { Male }=1\end{array}$ & $\begin{array}{c}\text { Female }=12 \\
\text { Male }=0\end{array}$ & $\begin{array}{c}\text { Female }=13 \\
\text { Male }=2\end{array}$ \\
\hline \multirow[t]{3}{*}{ Age (years) } & Schroth exercises & $\begin{array}{c}\text { Mean (range): } \\
13.5(12.7-14.2)\end{array}$ & $\begin{array}{c}\text { Mean (SD): } \\
15.6 \pm 1.1\end{array}$ & $\begin{array}{c}\text { Mean } \pm \text { SD: } \\
12.9 \pm 1.4\end{array}$ \\
\hline & Home exercises & - & - & $\begin{array}{c}\text { Mean } \pm \text { SD: } \\
13.1 \pm 1.7\end{array}$ \\
\hline & $\begin{array}{l}\text { Non-surgical } \\
\text { management }\end{array}$ & $\begin{array}{c}\text { Mean (range): } \\
13.3(12.7-13.9)\end{array}$ & $\begin{array}{c}\text { Mean (SD): } \\
15.3 \pm 0.8\end{array}$ & $\begin{array}{c}\text { Mean } \pm \text { SD: } \\
12.8 \pm 1.2 \\
\text { (range) } \\
(10-18)\end{array}$ \\
\hline $\begin{array}{l}\text { Inclusion } \\
\text { criteria }\end{array}$ & Cobb angle & $10^{\circ}-45^{\circ}$ & $\geq 20^{\circ}$ & $10^{\circ}-60^{\circ}$ \\
\hline PEDro scores & - & $8 / 10$ & $5 / 10$ & $6 / 10$ \\
\hline
\end{tabular}

Note: Studies by Schreiber et al. (2015) and Schreiber et al. (2016) were conducted in Canada. Study by Kim and HwangBo (2016) was conducted in Korea. Study by Kuru et al. (2016) was conducted in Turkey.

$\mathrm{SD}$, standard deviation.

(2016) used the same cohort but reported on different outcomes in two papers. All the articles specified gender distribution and had predominantly more female than male participants. The mean age of the participants among the studies ranged between 12.8 and 15.6 years. All the participants were diagnosed with AIS and were otherwise healthy. One of the 
articles was conducted in an upper-middle income country (Kuru et al. 2016) while the other articles were conducted in high-income countries (Kim \& HwangBo 2016; Schreiber et al. 2015, 2016).

\section{Description of intervention}

A comprehensive description of the interventions used across the four articles is outlined in Table 2. Variations in the dosages of Schroth exercises were evident across the four articles. The control groups were exposed to non-surgical management, which involved Pilates exercises, observation or bracing. Kuru et al. (2016) included two intervention groups and a control group. The first intervention group received supervised Schroth exercises, while the second intervention group were taught how to do Schroth exercises under the supervision and guidance of a physiotherapist. The second intervention group were asked to perform the exercises at home, and caregivers were asked to monitor compliance with the home programme.

\section{Description of outcome measures and assessment times}

The outcome measures and assessment times used in the four articles to assess spinal curvature (Cobb angle) and QOL are shown in Table 3. Standing posterior anterior radiographs were used to measure the Cobb angle in the three included articles (Kim \& HwangBo 2016; Kuru et al. 2016; Schreiber et al. 2016). Kuru et al. (2016) and Schreiber et al. (2015) made use of the SRS health-related QOL questionnaire (https://www.srs.org/professionals/onlineeducation-and-resources/patient-outcome-questionnaires).
It assesses health-related QOL specific to scoliosis and consists of five domains: function, pain, mental health, selfimage and satisfaction with management. The questionnaire has 22 (SRS-22) or 23 items (SRS-23) and a score between 0 and 5 is given to each item, 0 being the worst and 5 being the best (Kuru et al. 2016).

\section{The effect of Schroth exercises on the Cobb angle and quality of life}

The effect of Schroth exercises in the treatment of AIS is shown in Tables 4 and 5 under the following subheadings: Cobb angle and QOL.

\section{Cobb angle}

The means, standard deviations (SDs) and $p$-values for Cobb angle measurements are portrayed in Table 4.

Schreiber et al. (2016) measured the largest Cobb angle and found a significant difference $\left(95 \% \mathrm{CI}-5.9^{\circ}\right.$ to $\left.-1.1^{\circ} ; p=0.006\right)$ at 24 weeks in favour of the Schroth exercise group. The largest curve decreased in the Schroth exercise group by $1.2^{\circ}$ and increased by $2.3^{\circ}$ in the non-surgical management group. Kim and HwangBo (2016) showed a significant decrease in the Cobb angle for both groups $(p<0.05)$ at 12 weeks (intragroup analysis), while the intergroup analysis demonstrated a significant change in favour of the Schroth exercise group $(p<0.05)$. There were significant differences $(p=0.003)$ among the three groups in favour of the Schroth exercise group at 24 weeks in Kuru et al. (2016). The Cobb angle decreased in the supervised Schroth exercise group, while it increased in both the home exercise group and in the non-surgical management group.

TABLE 2: Description of intervention.

\begin{tabular}{|c|c|c|c|c|}
\hline Variable & Description & Schreiber et al. (2015) and Schreiber et al. (2016) & Kim and HwangBo (2016) & Kuru et al. (2016) \\
\hline \multirow[t]{2}{*}{$\begin{array}{l}\text { Intervention group: } \\
\text { Schroth exercises }\end{array}$} & Method & $\begin{array}{l}\text { Supervised Schroth physiotherapeutic scoliosis- } \\
\text { specific exercises (individual and group). }\end{array}$ & $\begin{array}{l}\text { Supervised Schroth } \\
\text { exercises }\end{array}$ & Supervised Schroth exercises. \\
\hline & $\begin{array}{l}\text { Dosages and frequency } \\
\text { of intervention }\end{array}$ & $\begin{array}{l}\text { Five individual sessions during first } 2 \text { weeks for } \\
60 \text { min, followed by weekly } 60 \text {-min group } \\
\text { sessions, in combination with } 30-45 \text { min home } \\
\text { exercise programme. Total duration of } 6 \text { months. } \\
\text { Total of } 5 \text { individual sessions and } 22 \text { group } \\
\text { sessions. }\end{array}$ & $\begin{array}{l}\text { Three times a week for } \\
12 \text { weeks for } 60 \text { min. } \\
\text { Total of } 36 \text { sessions }\end{array}$ & $\begin{array}{l}\text { Three days per week for } 6 \text { weeks for } 90 \text { min. } \\
\text { A total number of } 18 \text { sessions. } \\
\text { The programme was taught to the caregivers } \\
\text { as well, and after completion of the } 6 \text { week } \\
\text { programme, they performed the same programme } \\
\text { at home for a } 6 \text {-month period. }\end{array}$ \\
\hline \multirow[t]{2}{*}{$\begin{array}{l}\text { Home exercise } \\
\text { group }\end{array}$} & Method & - & - & $\begin{array}{l}\text { Schroth exercises were taught to the subjects under } \\
\text { the supervision and guidance of a physiotherapist, } \\
\text { and these patients were asked to perform the } \\
\text { exercises at home for a 6-month period. }\end{array}$ \\
\hline & $\begin{array}{l}\text { Dosages and frequency } \\
\text { of intervention }\end{array}$ & - & - & $\begin{array}{l}\text { No specific dosages or frequency. Caregivers were } \\
\text { asked if exercises were performed regularly to } \\
\text { check compliance. }\end{array}$ \\
\hline \multirow[t]{2}{*}{ Control group } & Method & $\begin{array}{l}\text { Observation or bracing in accordance to SRS } \\
\text { recommendations. }\end{array}$ & Pilates exercises & $\begin{array}{l}\text { No specific exercises. } \\
\text { Only observation. }\end{array}$ \\
\hline & $\begin{array}{l}\text { Dosage of non-surgical } \\
\text { management intervention }\end{array}$ & SRS recommended dosages. & $\begin{array}{l}\text { Three times a week for } \\
12 \text { weeks for } 60 \mathrm{~min}\end{array}$ & $\begin{array}{l}\text { Participants were observed (assessed) every } 6 \text { weeks } \\
\text { for a } 6 \text {-month period. }\end{array}$ \\
\hline
\end{tabular}

SRS, Scoliosis Research Society.

TABLE 3: Outcome measures used to measure spinal curvature and quality of life.

\begin{tabular}{|c|c|c|c|c|c|}
\hline Variable & Schreiber et al. (2015) & Schreiber et al. (2016) & Kim and HwangBo (2016) & Kuru et al. (2016) & Assessment intervals \\
\hline \multirow[t]{4}{*}{ Outcome measure } & QOL; SRS-22 & Cobb angle & Cobb angle & $\begin{array}{l}\text { Cobb angle } \\
\text { QOL; SRS-23 }\end{array}$ & Baseline \\
\hline & - & - & - & QOL; SRS-23 & 6 weeks \\
\hline & QOL; SRS-22 & - & Cobb angle & QOL; SRS-23 & 12 weeks \\
\hline & QOL; SRS-22 & Cobb angle & - & $\begin{array}{l}\text { Cobb angle } \\
\text { QOL; SRS-23 }\end{array}$ & 6 months \\
\hline
\end{tabular}

QOL, quality of life; SRS-22, Scoliosis Research Society 22-item questionnaire; SRS-23, Scoliosis Research Society 23-item questionnaire. 
TABLE 4: Means, standard deviations and $p$-values for Cobb angles measured at baseline, 12 weeks and 24 weeks.

\begin{tabular}{|c|c|c|c|c|c|c|c|}
\hline \multirow[t]{2}{*}{ Variable } & \multirow[t]{2}{*}{ Description } & \multicolumn{2}{|c|}{ Baseline } & \multicolumn{2}{|r|}{12 weeks } & \multicolumn{2}{|r|}{24 weeks } \\
\hline & & $\begin{array}{l}\text { Baseline } \\
\text { mean } \pm S D\end{array}$ & $\begin{array}{c}p \text {-value } \\
\text { (between groups) }\end{array}$ & $\begin{array}{c}\text { 12-week } \\
\text { mean } \pm \text { SD }\end{array}$ & $\begin{array}{l}p \text {-value (difference in } \\
\text { Cobb angle from baseline } \\
\text { between groups) }\end{array}$ & $\begin{array}{c}\text { 24-week } \\
\text { mean } \pm \text { SD }\end{array}$ & $\begin{array}{c}p \text {-value (difference in Cobb } \\
\text { angle from baseline } \\
\text { between groups) }\end{array}$ \\
\hline \multirow{2}{*}{$\begin{array}{l}\text { Schreiber et al. } \\
\text { (2016) }\end{array}$} & Schroth exercises & $29.1 \pm 8.9$ & \multirow[t]{2}{*}{$p>0.05$} & - & \multirow{2}{*}{ - } & $27.7 \pm 8.9$ & \multirow[t]{2}{*}{$p=0.006$} \\
\hline & Non-surgical management & $27.9 \pm 8.8$ & & - & & $29.1 \pm 8.8$ & \\
\hline \multirow{2}{*}{$\begin{array}{l}\text { Kim and } \\
\text { HwangBo (2016) }\end{array}$} & Schroth exercises & $23.6 \pm 1.5$ & \multirow{2}{*}{ - } & $12 \pm 4.7$ & \multirow[t]{2}{*}{$p<0.05$} & - & \multirow{2}{*}{ - } \\
\hline & Control group (Pilates exercise) & $24 \pm 2.6$ & & $16 \pm 6.9$ & & - & \\
\hline & Non-surgical management & $30.3 \pm 6.6$ & & - & \multirow[t]{2}{*}{-} & $33 \pm 6.9$ & \\
\hline & Home exercises & $30.3 \pm 7.6$ & & - & & $33.8 \pm 7.2$ & \\
\hline
\end{tabular}

SD, standard deviation.

TABLE 5: Means, standard deviations and $p$-values for quality of life measured at baseline, 6 weeks, 12 weeks and 24 weeks.

\begin{tabular}{|c|c|c|c|c|c|c|c|c|c|}
\hline \multirow[t]{2}{*}{ Variable } & \multirow[t]{2}{*}{ Description } & \multicolumn{2}{|c|}{ Baseline } & \multicolumn{2}{|c|}{6 weeks } & \multicolumn{2}{|r|}{12 weeks } & \multicolumn{2}{|r|}{24 weeks } \\
\hline & & $\begin{array}{c}\text { Baseline } \\
\text { mean } \pm S D\end{array}$ & $\begin{array}{c}p \text {-value } \\
\text { (between } \\
\text { groups) }\end{array}$ & $\begin{array}{c}\text { 6-week } \\
\text { mean } \pm \text { SD }\end{array}$ & $\begin{array}{c}p \text {-value } \\
\text { (between } \\
\text { groups) }\end{array}$ & $\begin{array}{c}\text { 12-week } \\
\text { mean } \pm S D\end{array}$ & $\begin{array}{l}p \text {-value (difference in } \\
\text { QOL from baseline } \\
\text { between groups) }\end{array}$ & $\begin{array}{c}\text { 24-week } \\
\text { mean } \pm \text { SD }\end{array}$ & $\begin{array}{l}p \text {-value (difference in } \\
\text { QOL from baseline } \\
\text { between groups) }\end{array}$ \\
\hline \multirow{2}{*}{$\begin{array}{l}\text { Schreiber } \\
\text { et al. (2015) }\end{array}$} & Schroth exercises & $4.25 \pm 0.25$ & - & - & - & $4.45 \pm 0.25$ & 0.001 & $4.40 \pm 0.25$ & 0.001 \\
\hline & Non-surgical management & $4.15 \pm 0.25$ & - & - & - & $4.18 \pm 0.25$ & & $4.15 \pm 0.25$ & \\
\hline \multirow{2}{*}{$\begin{array}{l}\text { Kuru et al. } \\
\text { (2016) }\end{array}$} & Schroth exercises & $3.9 \pm 0.6$ & 0.45 & $4.1 \pm 0.5$ & 0.11 & $4.2 \pm 0.5$ & 0.18 & $4.3 \pm 0.5$ & 0.13 \\
\hline & Home exercises & $3.9 \pm 0.4$ & & $4.0 \pm 0.5$ & & $4.1 \pm 0.4$ & & $4.1 \pm 0.3$ & \\
\hline
\end{tabular}

QOL, quality of life; SD, standard deviation.

\section{Quality of life}

The measurements of QOL are tabulated as the mean and SD in Table 5 using the SRS total score at baseline, 6 weeks, 12 weeks and 6 months. Schreiber et al. (2015) was the only study that found significant differences in favour of the Schroth exercise group at 12 weeks $(p=0.0005)$ and 24 weeks $(p=0.001)$.

When using a meta-analysis to combine the 12-week and 24-week data of Kuru et al. (2016) and Schreiber et al. (2015), the pooled effect showed a significant result in favour of Schroth exercises at 12 weeks $(p<0.002)$ (Figure 2) and at 24 weeks $(p<0.0004)$ (Figure 3).

\section{Discussion}

This is the first systematic review on the effectiveness of Schroth exercises compared to non-surgical management in decreasing the Cobb angle in adolescents with idiopathic scoliosis. Only four RCTs could be found comparing Schroth exercises to non-surgical management after a systematic search of seven databases. Our findings of the evidence suggested that a significant decrease in the Cobb angle can be expected after a 12-week (Kim \& HwangBo 2016) and/or a 24-week supervised Schroth exercise programme (Kuru et al. 2016; Schreiber et al. 2016) compared to nonsurgical management (see Table 5). A meta-analysis of the overall combined effect (Kuru et al. 2016; Schreiber et al. 2015) indicated that a statistically significant increase in the QOL was found in favour of supervised Schroth exercises at 12 weeks (Figure 2) and 24 weeks (Figure 3).

The treatment frequency and duration of Schroth exercises as a treatment modality differed considerably among the included articles. A meta-analysis conducted by Park et al. (2017) combined 15 studies and measured the pre-post effect size of Schroth exercises on idiopathic scoliosis. The treatment duration was found to be important as the method had a medium effect size ( $\geq 0.50)$, according to Cohen's guidelines (Durlak 2009), if applied for less than 6 months. They recommended that the treatment continue for at least 6 months or longer, as it has been shown to have a large effect size $(\geq 0.80)$ on the Cobb angle. It is interesting to note that the included article with the shortest treatment duration (12 weeks; Kim \& HwangBo 2016) also had the largest decrease in Cobb angles in both the Schroth exercise and Pilates groups (see Table 5). This finding is difficult to explain and may be attributed to the higher supervised treatment intensity, namely 36 supervised sessions for a duration of 12 weeks compared to Kuru et al. (2016), who used 18 supervised sessions for 6 weeks, and Schreiber et al. (2016), who included five supervised sessions during the first 2 weeks (see Table 2). Another explanation may be that Kim and HwangBo (2016) also included participants with smaller baseline Cobb angles comparing to Schreiber et al. (2015, 2016) and Kuru et al. (2016) (see Table 4). Park et al. (2017) compared the severity of pre-intervention Cobb angle ranges and reported that as the pre-intervention Cobb angle range increased, the effect sizes decreased. They found that Schroth exercises were much more beneficial for individuals with a pre-intervention Cobb angle range of less than $30^{\circ}$ (effect size of $\geq 0.80$ ), whereas Cobb angle ranges of $30^{\circ}-50^{\circ}$ and over $50^{\circ}$ showed only a moderate effect size.

Maintaining the improvement reached through supervised exercises with a home exercise programme is essential and the importance of compliance should be emphasised during treatment sessions, especially in countries with limited health resources. Patients who adhere to their prescribed home exercises are significantly better at achieving their goals and demonstrate a greater improvement in physical function (Jack et al. 2010). Unfortunately, research has shown that 


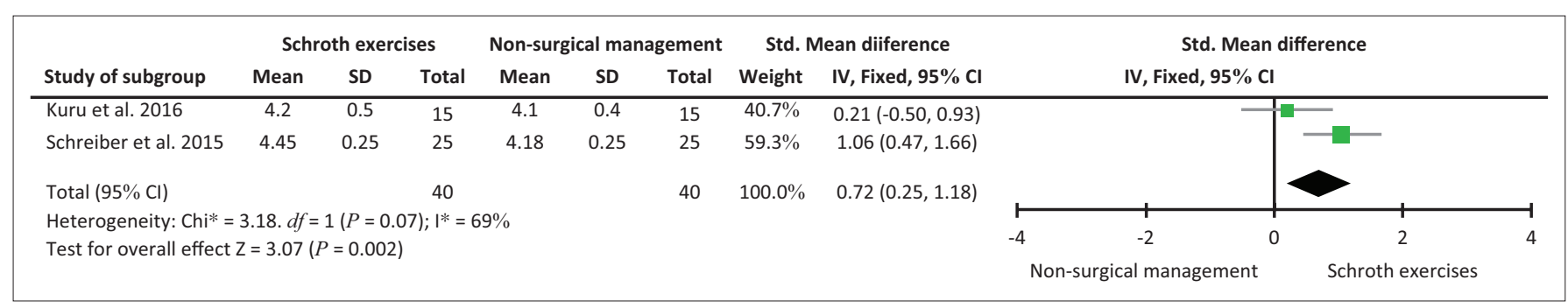

$\mathrm{Cl}$, confidence interval; SRS, Scoliosis Research Society.

FIGURE 2: Assessment of quality of life using the SRS-22 and SRS-23 questionnaire after 12 weeks.

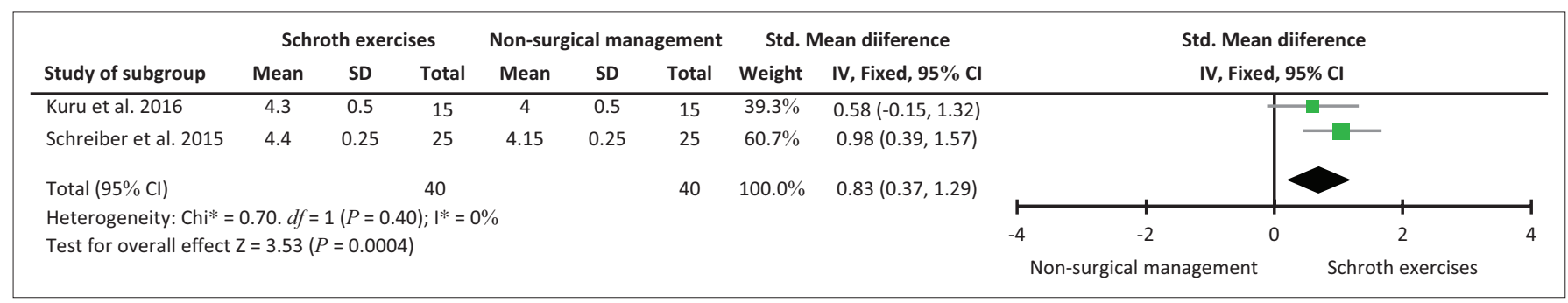

$\mathrm{Cl}$, confidence interval; SRS, Scoliosis Research Society; SD, standard deviation.

FIGURE 3: Assessment of quality of life using the SRS-22 and SRS-23 questionnaire after 24 weeks.

patients adhere poorly to prescribed home programmes, leading to less favourable functional outcomes (Jack et al. 2010). The success of the Schroth exercises is a responsibility shared by both the physiotherapist and the patient and relies on commitment. Schreiber et al. (2015) had a total compliance rate of $82.5 \%$ with regard to the home exercise programme, whereas the attendance rate of the exercise sessions was $85 \%$. The authors attributed the high compliance with the home exercises to the fact that they used exercise logbooks verified daily by the parents and weekly by the therapist (Schreiber et al. 2015). They recommended that compliance with the Schroth home programmes be maximised by providing basic home equipment, parental involvement and keeping a logbook (Schreiber et al. 2015). Kuru et al. (2016) were the only authors that stated that they educated the caregivers to ensure continuity of the supervised Schroth exercise programme as a home exercise programme. Kuru et al. (2016) included a third group, namely an unsupervised Schroth exercise home programme, in their study. The unsupervised home programme group yielded a similar progression and increase in the Cobb angle compared to the non-surgical management group. Kuru et al. (2016) concluded that the capacity for each child to learn and perform Schroth exercises effectively is different and a considerable amount of time should be invested to teach home Schroth exercises to ensure a better outcome. Kim and HwangBo (2016) were the only authors who compared Schroth exercises to Pilates. The exercises that were prescribed in the Pilates group were spinal-correction, balance and core-strengthening exercises with trunk breathing, while the Schroth exercises were prescribed according to the curve shape of each participant. Both Schroth and Pilates showed significant improvement in the Cobb angle; however, the Schroth exercise group proved to be more effective in decreasing the Cobb angle.

The methodological quality of the individual articles ranged from average $(5 / 10)$ to high $(8 / 10)$ on the PEDro scale.
Because of the nature of the study designs, none of the included studies was able to blind the subjects or the therapists. Kim and HwangBo (2016) and Kuru et al. (2016) did not blind the assessor, and this could have led to observer or detection bias in the individual studies (Hróbjartsson et al. 2012). Kim and HwangBo (2016) did not apply concealed allocation, thus decreasing the internal validity of their study by causing selection bias, which may have influenced the type of treatment that the patients received (Poolman et al. 2007).

The strengths of this review are that a comprehensive and systematic search strategy, including seven computerised scientific databases, was utilised. This review was conducted in a documented stepwise manner. Each step involved two independent authors, and cross-checking was done by the rest of the group, limiting potential errors and encouraging objectivity. A limitation of this review was that only four RCTs met the inclusion criteria. Two of these RCTs used the same cohort (Schreiber et al. 2015, 2016), and both outcomes, QOL and Cobb angle, were only included in one article (Kuru et al. 2016).

Only English papers were included, which could present as possible language bias. However, language translations of studies could not be achieved in the context of this review, as resources and time were limited. Longer-term measurement, including younger adolescents (not at the end of their growth phase), would have strengthened the outcomes.

Higher degrees of scoliosis have many secondary complications (Altaf et al. 2013; Asher \& Burton 2006), which necessitates a holistic approach to the management in young adolescents. This review's positive findings regarding the effectiveness of Schroth exercises in decreasing Cobb angles and improving QOL should be considered with caution for physiotherapy practice because of the limited number of 
identified articles and their methodologic limitations. Based on the current available and limited evidence, clinicians could combine supervised Schroth exercises with conventional physiotherapy care (observation, exercise, bracing and manual therapy) when treating adolescents with idiopathic scoliosis. It is recommended that a well-structured supervised Schroth home exercise programme be incorporated to optimise outcomes. Schroth exercises do not require expensive equipment, making them very applicable and feasible in the South African context. One of the included articles, with an average PEDro score, found that a decrease in the Cobb angle can be expected after 12 weeks of supervised Schroth exercises, with a frequency of at least three times a week for $60 \mathrm{~min}$ (Kim \& HwangBo 2016). Three hour-appointments per week for 12 weeks may however be challenging in an under-resourced physiotherapy department and not applicable in the South African context.

Researchers should definitely explore the different domains of QOL, as implemented in Schreiber et al. (2015). Pain, function and self-image are all factors affected by scoliosis, but some to a greater extent than others. It is thus necessary to do further investigation into the outcomes of these individual aspects of QOL and how Schroth exercises affect each of them. This could produce a clearer idea as to where the true improvement lies and also determine what other strategies could be implemented to achieve a better outcome concerning QOL. To determine the long-term effect and sustainability of supervised and home Schroth exercise programmes, long-term studies should be conducted with follow-up assessments at 12 months after completion of the supervised programme. The included studies compared Schroth exercises to non-surgical management, which included bracing and observation as well as Pilates. Because not offering a brace to participants meeting the brace prescription criteria is an ethical concern; Schreiber et al. $(2015,2016)$ included an equal number of participants $(n=17)$ wearing braces in their Schroth exercise and non-surgical management group. Future studies can look at Schroth exercises combined with brace wearing compared to brace wearing alone and/or observation without brace wearing in participants not yet meeting brace prescription criteria. Because only one of the studies included in this systematic review was not conducted in a high-income country (Kuru et al. 2016), similar studies can be conducted in low or middle-income countries, such as South Africa, to determine the effectiveness of Schroth exercise for adolescents with idiopathic scoliosis in various clinical settings.

\section{Conclusion}

In conclusion, Level II evidence suggests that Schroth therapeutic intervention has a significant effect on improving regression of the Cobb angle as well as improving the QOL in adolescents with idiopathic scoliosis, for up to 6 months postintervention, when compared to non-surgical management alone.
However, the limited number of identified articles and their methodological shortcomings require caution in interpreting and applying these results. Consequently, further high quality studies should consider the different domains of QOL to evaluate the holistic effect that Schroth exercises can have on the management of scoliosis as well as the long-term effect of Schroth exercises on the Cobb angle.

\section{Acknowledgements Competing interests}

The authors declare that they have no financial or personal relationships that may have inappropriately influenced them in writing this article.

\section{Authors' contributions}

M.B. was the project leader and responsible for the conception and design of the study, revising the manuscript critically for important intellectual content and approving the final version to be published. All the authors were responsible for searching the databases and reviewing and scoring the included papers. The extracted data were cross-checked by all the research team members (M.B., W.C., L.D.P., L.G., F.J., E.M., C.V.R., N.V.).

\section{Funding}

This research received no specific grant from any funding agency in the public, commercial, or not-for-profit sectors.

\section{Data availability statement}

Data sharing is not applicable to this article as no new data were created or analysed in this study.

\section{Disclaimer}

The views and opinions expressed in this article are those of the author(s) and do not necessarily reflect the official policy or position of any affiliated agency of the authors.

\section{References}

Agabegi, S., Kazemi, N., Sturm, P. \& Mehlman, C., 2015, 'Natural history of adolescent idiopathic scoliosis in skeletally mature patients: A critical review', Journal of the American Academy of Orthopaedic Surgeons 23(12), 714-723. https://doi.org/ 10.5435/JAAOS-D-14-00037

Altaf, F., Gibson, A., Dannawi, Z. \& Noordeen, H., 2013, 'Adolescent idiopathic scoliosis', British Medical Journal 346(1), f2508. https://doi.org/10.1136/bmj.f2508

Asher, M.A. \& Burton, D.C., 2006, 'Adolescent idiopathic scoliosis: Natural history and long term treatment effects', Scoliosis 1(2), 1-10. https://doi.org/10.1186/17487161-1-2

Berdishevsky, H., Lebel, V., Bettany-Saltikov, J., Rigo, M., Lebel, A., Hennes, A. et al., 2016, 'Physiotherapy scoliosis-specific exercises - A comprehensive review of seven major schools', Scoliosis and Spinal Disorders 11(1), 1-52. https://doi.org/ 10.1186/s13013-016-0076-9

Blum, C.L., 2002, 'Chiropractic and pilates therapy for the treatment of adult scoliosis', Journal of Manipulative and Physiological Therapeutics 25(4), E1-E8. https://doi. org/10.1067/mmt.2002.123336

Canavese, F. \& Kaelin, A., 2011, 'Adolescent idiopathic scoliosis: Indications and efficacy of nonoperative treatment', Indian Journal of Orthopaedics 45(1), 7-14. https://doi.org/10.4103/0019-5413.73655

Cheng, J., Castelein, R., Chu, W., Danielsson, A., Dobbs, M., Grivas, T. et al., 2017 'Adolescent idiopathic scoliosis', Nature Reviews Disease Primers, viewed 08 October 2017, from http://europepmc.org/abstract/med/27188385. 
Choudhry, M.N., Ahmad, Z. \& Verma, R., 2016, 'Adolescent idiopathic scoliosis', The Open Orthopaedics Journal 10, 143-154. https://doi.org/10.2174/1874325001610010143

Coleman, K., Norris, S., Weston, A., Grimmer-Somers, K., Hillier, S., Merlin, T. et al., 2009, 'NHMRC additional levels of evidence and grades for recommendations for developers of guidelines', BMC Medical Research Methodology 9(34), 1-23.

De Morton, N.A., 2009, 'The PEDro scale is a valid measure of the methodological quality of clinical trials: A demographic study', Australian Journal of Physiotherapy 55(2), 129-133. https://doi.org/10.1016/S0004-9514(09)70043-1

Durlak, J., 2009, 'How to select, calculate, and interpret effect sizes', Journal of Pediatric Psychology 34(9), 917-928. https://doi.org/10.1093/jpepsy/jsp004

Fusco, C., Zaina, F., Atanasio, S., Romano, M., Negrini, A. \& Negrini, S., 2011, 'Physical exercises in the treatment of adolescent idiopathic scoliosis: An updated systematic review', Physiotherapy Theory Practice 27(1), 80-114. https://doi.org/ 10.3109/09593985.2010.533342

Hróbjartsson, A., Sofia, A. \& Thomsen, S., 2012, 'Observer bias in randomised clinical trials with binary outcomes: Systematic review of trials with both blinded and non-blinded outcome assessors', British Medical Journal 1119, 1-11. https://doi. non-blinded outcome asses
org/10.1136/bmj.e1119

Jack, K., McLean, S.M., Moffett, J.K. \& Gardiner, E., 2010, 'Barriers to treatment adherence in physiotherapy outpatient clinics: A systematic review', Manual Therapy 15, 220-228. https://doi.org/10.1016/j.math.2009.12.004

Katz, D.E. \& Durrani, A.A., 2001, 'Factors that influence outcome in bracing large curves in patients with adolescent idiopathic scoliosis', Spine 26(21), 2354-2361. https://doi.org/10.1097/00007632-200111010-00012

Kim, G. \& HwangBo, P., 2016, 'Effects of Schroth and Pilates exercises on the Cobb angle and weight distribution of patients with scoliosis', Journal of Physical Therapy Science 28(3), 1012-1015

Kuru, T., Yeldan, I., Dereli, E., Özdinçler, A., Dikici, F. \& Çolak, i., 2016, 'The efficacy of three-dimensional Schroth exercises in adolescent idiopathic scoliosis: A randomised controlled clinical trial', Clinical Rehabilitation 30(2), 181-190. https://doi.org/10.1177/0269215515575745

Liberati, A., Altman, D.G., Tetzlaff, J., Mulrow, C., Gøtzsche, P.C., loannidis, J.P. et al., 2009, 'The PRISMA statement for reporting systematic reviews and meta-analyses of studies that evaluate health care interventions: Explanation and elaboration' PLoS Medicine 6(7), e1000100. https://doi.org/10.1371/journal.pmed.1000100

Lewis, C., 2012, 'A review of non-invasive treatment interventions for spinal deformities', Physical Therapy Perspectives in the 21st Century - Challenges and Possibilities 3, 67-88.

Monticone, M., Ambrosini, E., Cazzaniga, D., Rocca, B. \& Ferrante, S., 2014, 'Active self-correction and task-oriented exercises reduce spinal deformity and improve quality of life in subjects with mild adolescent idiopathic scoliosis-results of a randomised controlled trial', European Spine Journal 23(6), 1204-1214. https:// doi.org/10.1007/s00586-014-3241-y

Morrissy, R.T., Goldsmith, G.S., Hall, E.C., Kehl, D. \& Cowie, G.H., 1990, 'Measurement of the Cobb angle on radiographs of patients who have', Journal of Bone \& Joint Surgery American Volume 72(3), 320-327. https://doi.org/10.2106/00004623199072030-00002

Negrini, S., Minozzi, S., Bettany-Saltikov, J., Zaina, F., Chockalingam, N., Grivas, T. et al ., 2010, 'Braces for idiopathic scoliosis in adolescents', Spine 35(13), 1285-1293. 2010, 'Braces for idiopathic scoliosis in adolesc
https://doi.org/10.1097/BRS.0b013e3181dc48f4

National Health and Medical Research Council (NHMRC), 2009, NHMRC additional levels of evidence and grades for recommendations for developers of guidelines, NHMRC, Canberra, viewed 01 April 2018, from http://www.nhmrc.gov.au/ files nhmrc/file/guidelines/stage_2 consultation_levels_and grades.pdf.
Park, J.H., Jeon, H.S. \& Park, H.W., 2018, 'Effects of the Schroth exercise on idiopathic scoliosis: A meta-analysis', European Journal of Physical and Rehabilitation Medicine 54(3), 440-449. https://doi.org/10.23736/S1973Rehabilitation Med

Poolman, R.W., Struijs, P.A., Krips, R., Sierevelt, I.N., Marti, R.K., Farrokhyar, F. et al., 2007, 'Reporting of outcomes in orthopedic randomized trials: Does blinding of outcome assessors matter?', Journal of Bone Joint Surgery 89(3), 550-558.

Ramirez, N., Johnston, C.E.I. \& Browne, R.H., 1997, 'The prevalence of back pain in children who have idiopathic scoliosis', Journal of Bone and Joint Surgery 79(3), 364-368. https://doi.org/10.2106/00004623-199703000-00007

Reichel, D. \& Schanz, J., 2003, 'Developmental psychological aspects of scoliosis treatment', Pediatric Rehabilitation 6(3-4), 221-225.

RevMan, 2008, IMS Cochrane, viewed 15 June 2018, from http://ims.cochrane.org/ revman.

Richards, B., Bernstein, R., D'Amato, C. \& Thompson, G., 2005, 'Standardization of criteria for adolescent idiopathic scoliosis brace studies', Spine 30(18), 2068-2075. https://doi.org/10.1097/01.brs.0000178819.90239.d0

Rigo, M., Negrini, S., Weiss, H., Grivas, T., Maruyama, T. \& Kotwicki, T., 2006, 'SOSORT consensus paper on brace action: TLSO biomechanics of correction-investigating the rationale for force vector selection', Scoliosis 1(1), 1. https://doi.org/ the rationale for force
$10.1186 / 1748-7161-1-11$

Romano, M., Minozzi, S., Zaina, F., Chockalingam, N., Kotwicki, T., Hennes, A. et al., 2012, 'Exercises for adolescent idiopathic scoliosis-review', Cochrane Database of Systematic Reviews 8, 10-12.

Romano, M., Minozzi, S., Zaina, F., Saltikov, J., Chockalingam, N., Kotwicki, T. et al., 2013, 'Exercises for adolescent idiopathic scoliosis', Spine 38(14), E883-E893. https://doi.org/10.1097/BRS.0b013e31829459f8

Schreiber, S., Parent, E., KhodayariMoez, E., Hedden, D., Hill, D., Moreau, M. et al., 2016 'Schroth physiotherapeutic scoliosis-specific exercises added to the standard of care lead to better Cobb angle outcomes in adolescents with idiopathic scoliosis - An assessor and statistician blinded randomized controlled trial', PLOS One 11(12), 1-17. https://doi.org/10.1371/journal.pone.0168746

Schreiber, S., Parent, E.C., Moez, E.K., Hedden, D.M., Hill, D., Moreau, M.J. et al., 2015 'The effect of Schroth exercises added to the standard of care on the quality of life and muscle endurance in adolescents with idiopathic scoliosis - An assessor and statistician blinded randomized controlled trial: SOSORT 2015 award winner', Scoliosis 10(1), 24. https://doi.org/10.1186/s13013-015-0048-5

Scoliosis Research Society, viewed 15 June 2018, from https://www.srs.org/ professionals/online-education-and-resources/patient-outcome-questionnaires.

Vasiliadis, E. \& Grivas, T., 2008, 'Quality of life after conservative treatment of adolescent idiopathic scoliosis', Studies in Health Technology and Informatics 135 409-413.

Verhagen, A.P., De Vet, H.C., De Brie, R.A., Kessels, A.G., Broers, M., Bouter, L. et al. 1998, 'The Delphi list: A criteria for quality assessment of randomised clinical trials for conducting systematic reviews developed by Delphi consensus' clinical trials for conducting systematic reviews developed by Delphi consensus,
Journal of Clinical Epidemiology 51(12), 1235-1241. https://doi.org/10.1016/ Journal of Clinical Epidemi

Weinstein, S.L., Dolan, L.A., Cheng, J.C.Y, Danielsson, A. \& Morcuende, J.A., 2008 'Adolescent idiopathic scoliosis', Lancet 371, 1527-1537. https://doi.org/10.1016/ Adolescent idiopathic scolio

Weiss, H., Weiss, G. \& Petermann, F., 2003, 'Incidence of curvature progression in idiopathic scoliosis patients treated with scoliosis in-patient rehabilitation (SIR): An age- and sex-matched controlled study', Pediatric Rehabilitation 6(1), 23-30. https://doi.org/10.1080/1363849031000095288 